\title{
A CPW-fed triangular monopole antenna with staircase ground for UWB applications
}

\author{
Madhuri K. Kulkarni*, Veeresh G. Kasabegoudar \\ Post Graduate Department, Mahatma Basveshwar Education Society’s, College of Engineering, Ambajogai, India, 431517
}

Email address:

kulkarni3388@gmail.com (M. K. Kulkarni), veereshgk2002@rediffmail.com (V. G. Kasabegoudar)

To cite this article:

Madhuri K. Kulkarni, Veeresh G. Kasabegoudar. A CPW-Fed Triangular Monopole Antenna with Staircase Ground for UWB Applications. International Journal of Wireless Communications and Mobile Computing. Vol. 1, No. 4, 2013, pp. 129-135. doi: 10.11648/j.wcmc.20130104.18

\begin{abstract}
In this paper, a monopole antenna with triangular shaped patch based on coplanar waveguide (CPW)-feed is presented. The proposed antenna comprises a planar triangular patch element with a staircase ground which offers ultra wide bandwidth. The impedance bandwidth can be tuned by changing staircase shaped ground parameters (number of steps, step length, and/or its width). The overall size of the antenna is $28 \mathrm{~mm} \times 26 \mathrm{~mm} \times 1.6 \mathrm{~mm}$ including finite ground CPW feeding mechanism. The antenna operates in the frequency range from 3.2-12 $\mathrm{GHz}$ covering FCC defined UWB band with more than $100 \%$ impedance bandwidth. Stable omni-directional radiation patterns in the desired frequency band have been obtained. Measured data fairly agree with the simulated results.
\end{abstract}

Keywords: Microstrip Antenna, Coplanar Waveguide, and Monopole Antenna

\section{Introduction}

Due to increasing demands of wireless communication systems it is necessary to design antenna with compact size, wide bandwidth, and low profile [1]. One of the best choices for this is planar monopole antennas. These are low profile, etched on a dielectric substrate and can provide feature of broadband and multiband. Planar monopole antennas can be used for UWB applications due to their wideband characteristics $[2,3]$.

The FCC authorization for the unlicensed use of UWB in the frequency range of 3.1 to $10.6 \mathrm{GHz}[4]$ encourages the designers to go for UWB antennas. It is well known that the CPW feed offers several advantages over microstrip feeds such as ease of mounting electronic components due to coplanar nature, no need to drill through substrate, and easy transition to slot line [5]. Hence, these feeds are preferred for applications where size is the constraint. There are several CPW fed antennas presented in the literature for UWB applications [6-14]. Antenna reported in [6] is CPW- fed fractal slot antenna which is having omni-directional radiation patterns over the operating frequency band. Another CPW-fed ultra-wideband (UWB) antenna with dual band-notched characteristics presented in [7] has little interference among WLAN and WiMAX. A compact CPW fed UWB antenna reported in [8] is designed using copper tape as radiating element and denim textile as substrate.
However, the radiation patterns of this geometry are not omni-directional over the entire operating frequency band. CPW-fed tapered ring slot antenna reported in [9] is limited by distorted radiation patterns. Most of the antennas presented in literature have complex geometry or large ground planes [10-12]. In this work, a coplanar waveguide fed triangular monopole antenna is presented. The antenna presented here is simple in structure and has a compact size. The proposed antenna consists of an inverted triangular strip with staircase shaped ground. Also, by modifying the ground geometry dual band characteristics can be obtained. The antenna is simulated using Ansoft's High Frequency Structure Simulator (HFSS) v.10 [15]. More details on this geometry are discussed in subsequent sections. Section 2 presents the geometry structure of the proposed antenna. Design and optimization procedure of the proposed antenna is presented in Section 3. Section 4 presents the validation of the fabricated prototype and discussions on the measured results are also presented there. Finally, conclusions of this study are presented in Section 5.

\section{Antenna Geometry}

Figure 1(a) shows the basic geometry of proposed triangular monopole antenna for UWB operation. The antenna is symmetrical with respect to the longitudinal direction. Substrate used for the design is FR4 with thickness of $1.6 \mathrm{~mm}$, dielectric constant of 4.4 , and loss 
tangent equal to 0.02 . Two equal finite ground planes, each with dimensions of length $L_{g}$ and width $W_{g}$ are placed symmetrically on either side of the CPW feed-line. It is well known that defected ground structure (DGS) helps in reducing the overall size of antenna [16], a staircased profile DGS has been introduced in the ground plane of proposed antenna. Besides reducing the size, DGS also alters the reactive part of the antenna's input impedance [17] and hence impedance bandwidth of the antenna may be tuned. Detailed analysis of modification of ground structure and its effect is discussed in Section 3.1. Triangular shaped patch with rectangular base is fed by signal conductor. The detailed optimization procedure of the proposed antenna and its optimum dimensions, and characteristics are presented in Section 3. All the parameters of the geometry are indicated in Figure 1(a).

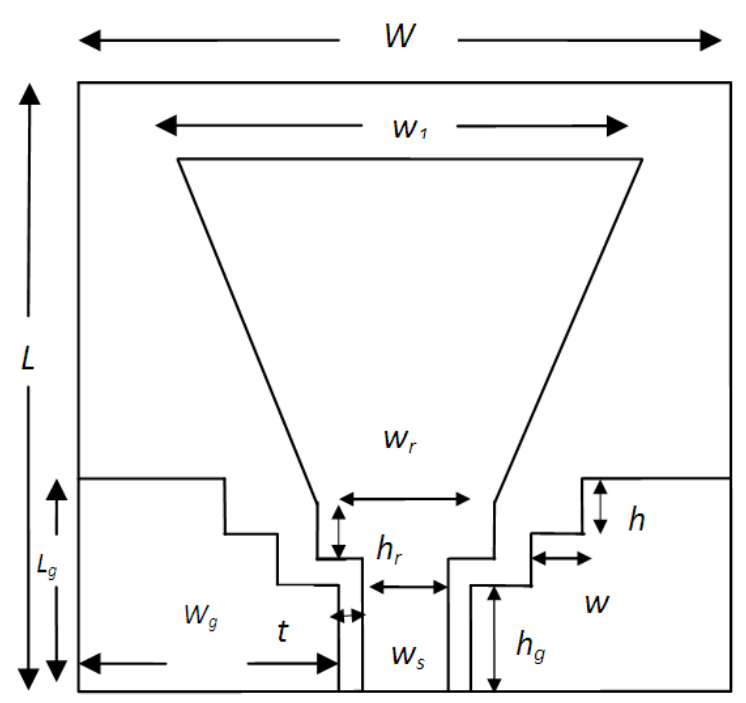

(a) Geometry

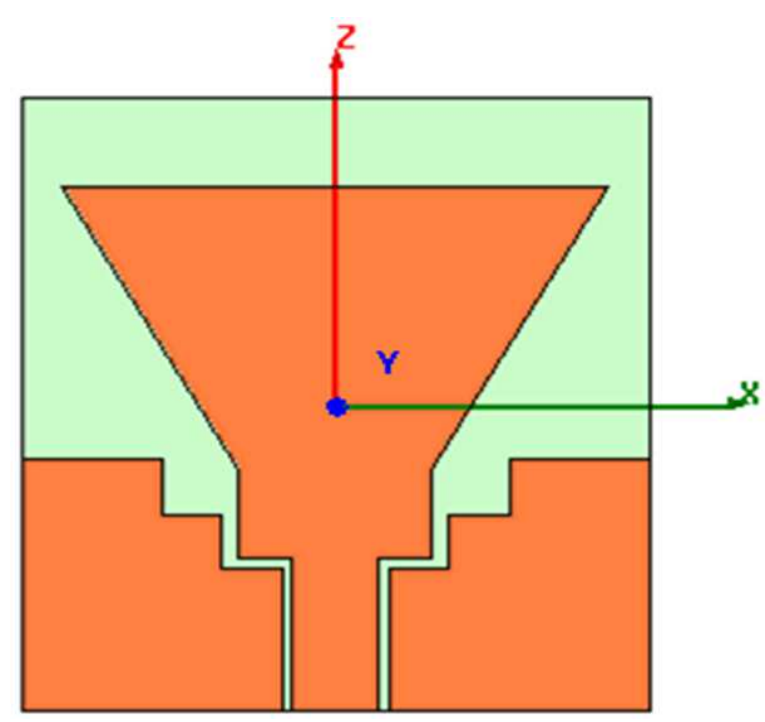

(b) Simulation setup in HFSS

Figure 1. Geometry of proposed CPW-fed monopole antenna.

\section{Geometry Optimization and Discussions}

In this section parametric study is conducted to optimize the proposed antenna. The key design parameters used for the optimization are number of steps in the staircase shaped ground plane, length and width of the staircase profile, and rectangular base dimensions. The detailed analysis of these parameters is investigated in the following paragraphs of this section.

\subsection{Effect of Ground Geometry}

As showed in Figure 2, ground plane of the geometry is modified to see its effect on the performance of antenna. For this, ground plane is changed to staircase shape. The number of steps in the staircase shaped geometry is changed from zero to three. In order to understand the effect of number steps in the staircase profile on radiation performance of the geometry, surface currents distributions on the geometry have been investigated (Figure 2). From the currents distribution on the geometry it may be noted that staircase ground with two steps exhibits better radiation than others. Furthermore, sharp edges of the staircase have been changed to smooth edges. Except slight improvement in the impedance bandwidth no significant change in the performance of the geometry was observed. However, smooth transitions in the geometry may be adopted if beam tilting is the major issue i.e., to avoid the beam tilting [18].

Return loss characteristics of this study are presented in Figure 3. From Figure 3 it may be noted that with two steps in the ground offers wide bandwidth whereas for one step, the return loss characteristics split in the middle. The optimum height and width for each step is achieved in two steps. In the first attempt height of the staircase is varied in steps of $0.5 \mathrm{~mm}$ by keeping its width and all other parameters constant. After optimizing the height, width of the staircase is optimized. Figures 4 and 5 show return loss characteristics plots of this study. From these figures it may be noted that the wide bandwidth can be obtained for $h=2.5 \mathrm{~mm}$ and $w=2.5 \mathrm{~mm}$. The percentage bandwidths obtained from these parametric studies are presented in Tables $1 \& 2$.
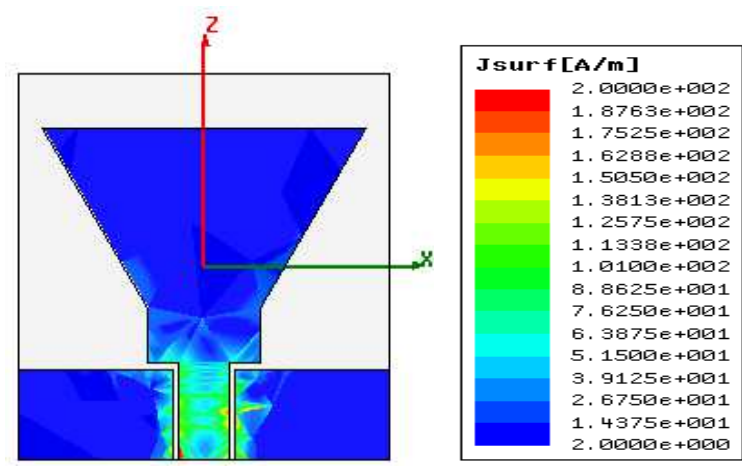

a) No step 

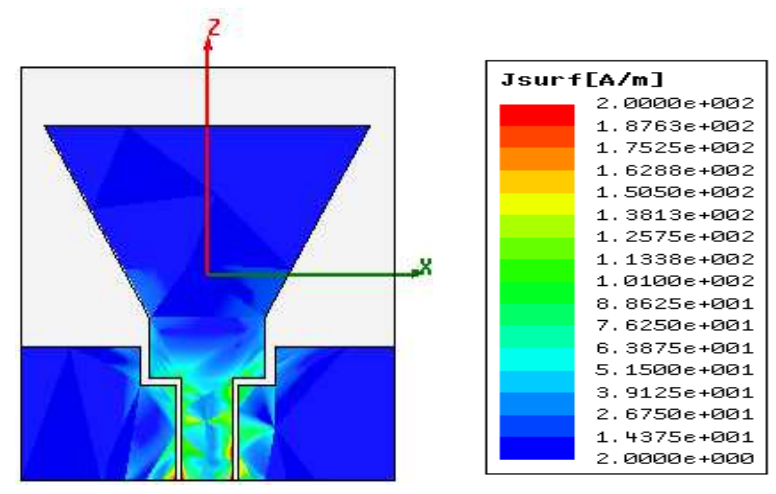

b) One step

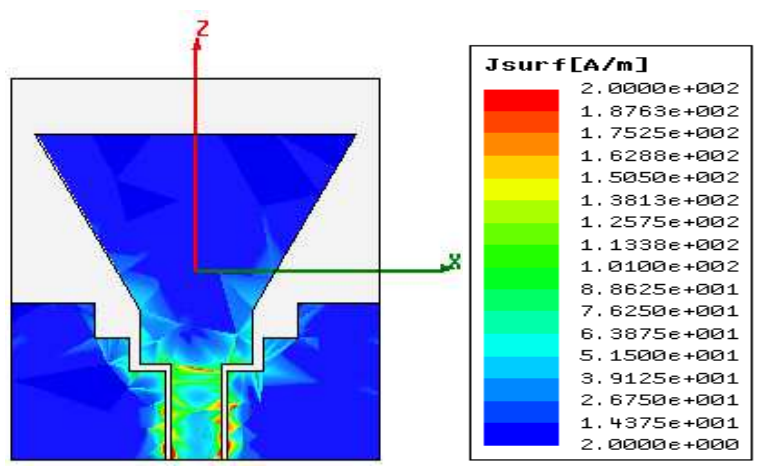

c) Two steps
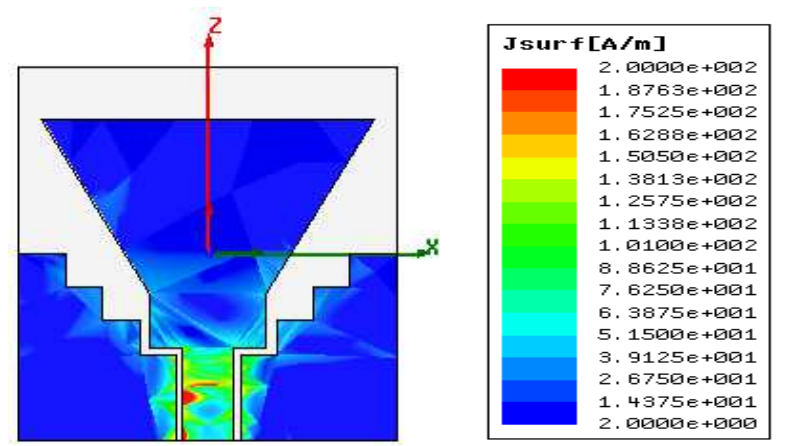

d) Three steps

Figure 2. Variation in number of steps in the staircase profile of ground and current distributions.

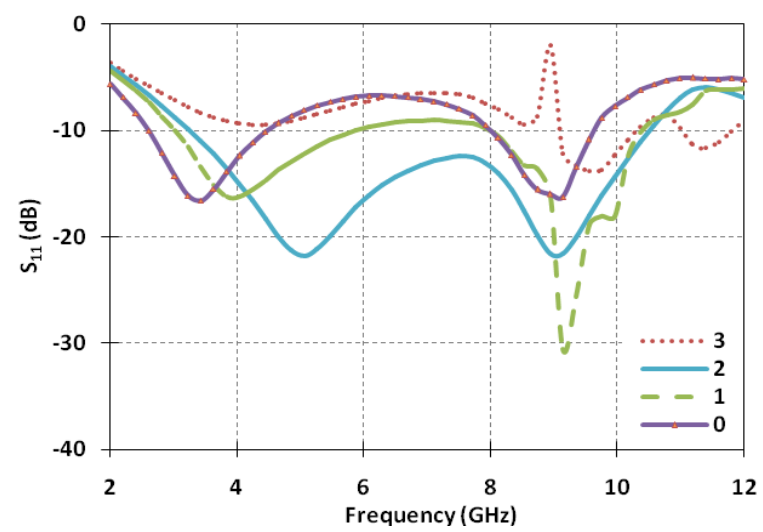

Figure 3. Return loss vs. frequency plot for variation in number of steps as indicated in Figure 2.

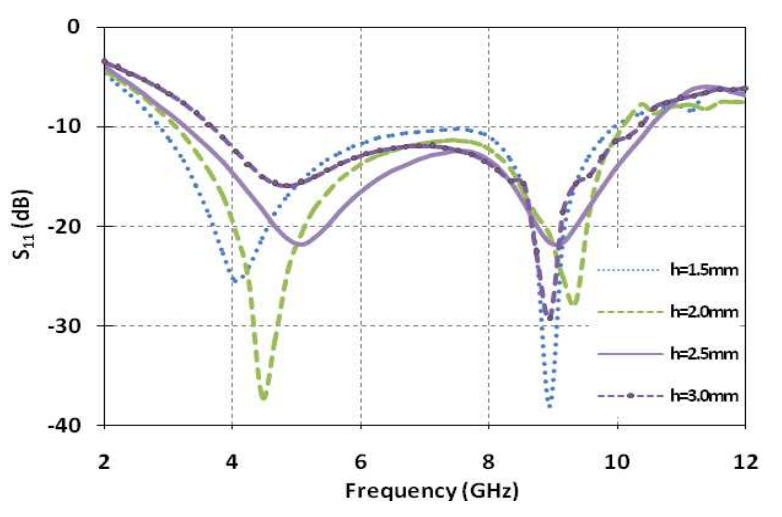

Figure 4. Return loss vs. frequency plot for variable step height (h).

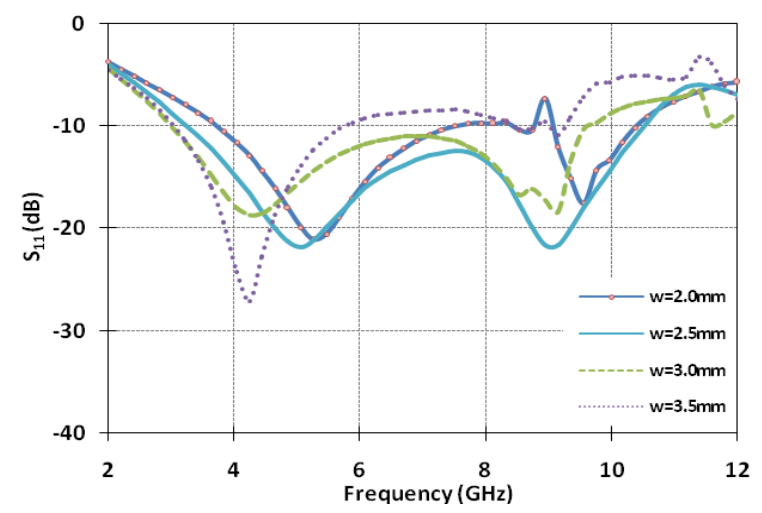

Figure 5. Return loss vs. frequency plot for variable step width (w).

Table 1. Effect of variation of step height on bandwidth of proposed antenna.

\begin{tabular}{ccc}
\hline Step height $(\boldsymbol{h})(\mathbf{m m})$ & Frequency range $(\mathbf{G H z})$ & Bandwidth $(\%)$ \\
\hline 1.5 & $2.81-7.51$ & 91.08 \\
2.0 & $3.22-10.16$ & 103.73 \\
2.5 & $3.22-10.57$ & 106.67 \\
3.0 & $3.63-10.36$ & 96.28 \\
\hline
\end{tabular}

Table 2. Effect of variation of step width on bandwidth of proposed antenna with height $=2.5 \mathrm{~mm}$.

\begin{tabular}{ccc}
\hline Step width $(\mathbf{w})(\mathbf{m m})$ & Frequency range $(\mathbf{G H z})$ & Bandwidth (\%) \\
\hline 2.0 & $3.83-7.51$ & 64.90 \\
2.5 & $3.22-10.57$ & 106.67 \\
3.0 & $3.02-9.55$ & 103.98 \\
3.5 & $3.02-5.87$ & 64.18 \\
\hline
\end{tabular}

\subsection{Effect of Rectangular Base Dimensions}

To study the effect of rectangular base dimensions on the antenna performance, its height $\left(h_{r}\right)$ and width $\left(w_{r}\right)$ are varied. Figures 6 (a) and (b) depict the current distributions on triangular monopole antenna without and with rectangular base. From the current distribution it is clear that better radiation effect can be observed in triangular 
monopole antenna mounted on rectangular base. This is mainly due to additional loading of reactance part to antenna's input impedance [17] and hence input impedance of the whole geometry can be fine tuned to get optimum performance. As in the case of staircase profile, edges of rectangular base was also made smooth but no significant improvement was obtained.

Initially, the height of the rectangle $\left(h_{r}\right)$ is varied from $3 \mathrm{~mm}$ to $4.5 \mathrm{~mm}$ in steps of $0.5 \mathrm{~mm}$ keeping width of the rectangular base constant $(8 \mathrm{~mm})$. These effects on return loss characteristics are presented in Figure 7. From Figure 7, it may be noted that the lower cut-off frequency remains nearly constant whereas upper cut-off frequency varies slightly i.e., impedance bandwidth varies with respect to this parameter $\left(h_{r}\right)$. From Table 3 it is found that $h_{r}=4 \mathrm{~mm}$ offers the maximum bandwidth of $106.67 \%$. With this optimum height $\left(h_{r}\right)$, width of the base $\left(w_{r}\right)$ was varied from $6.5 \mathrm{~mm}$ to $8.5 \mathrm{~mm}$ in steps of $0.5 \mathrm{~mm}$. Effect of width on return loss characteristics of the antenna are presented in Figure 8. Tables $3 \& 4$ illustrate the effect of $h_{r}$ and $w_{r}$ on percentage bandwidth. Accordingly, the optimum values of $h_{r}$ and $w_{r}$ are found to be $4 \mathrm{~mm}$ and $8 \mathrm{~mm}$, respectively.
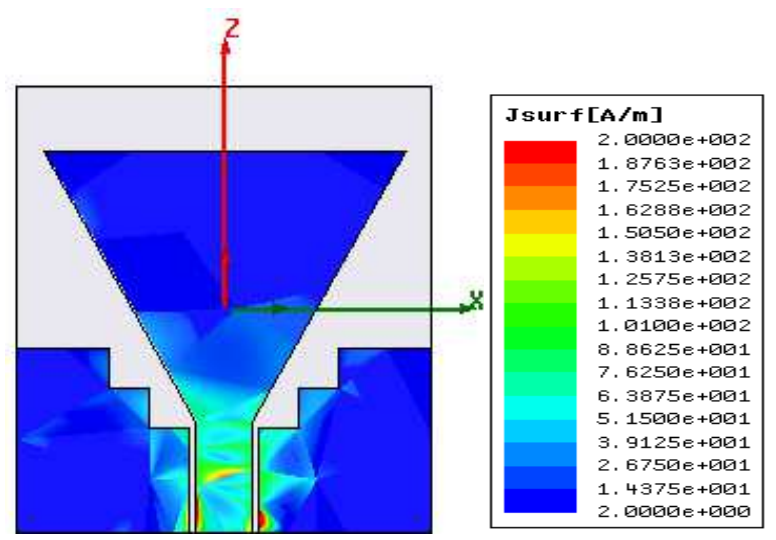

(a) Geometry without rectangular base

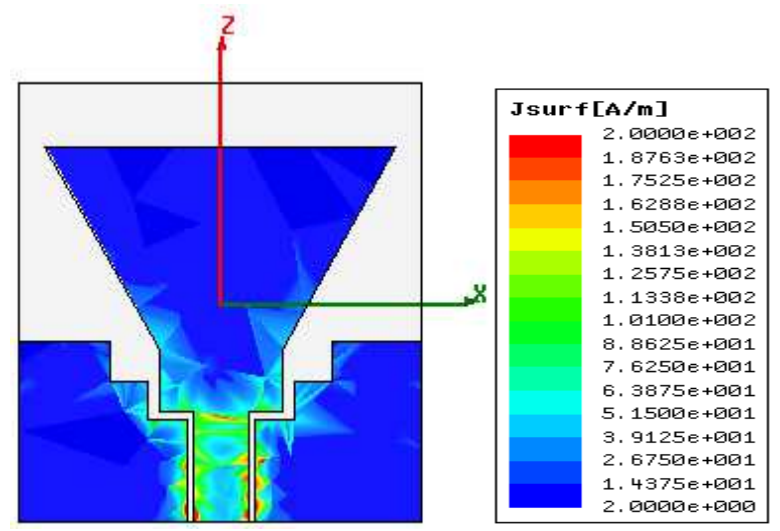

(b) Geometry with rectangular base

Figure 6. Current distribution to show effect of rectangular base below triangular patch.

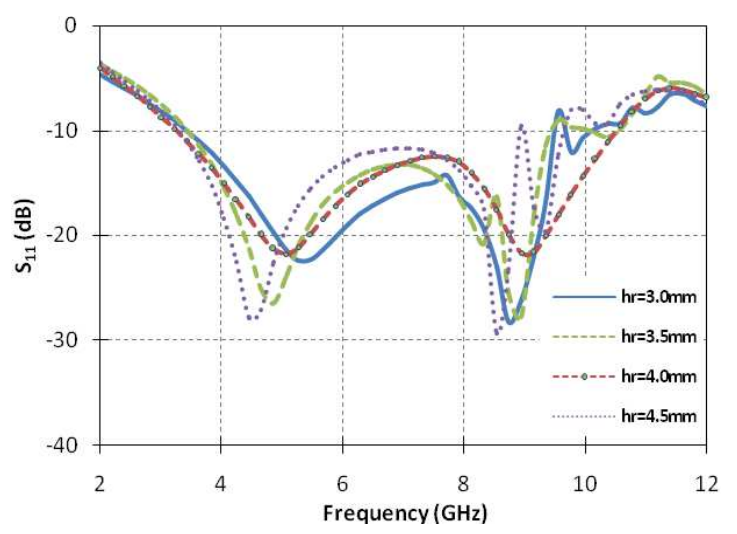

Figure 7. Return loss vs. frequency plot with variable rectangle height $\left(h_{r}\right)$.

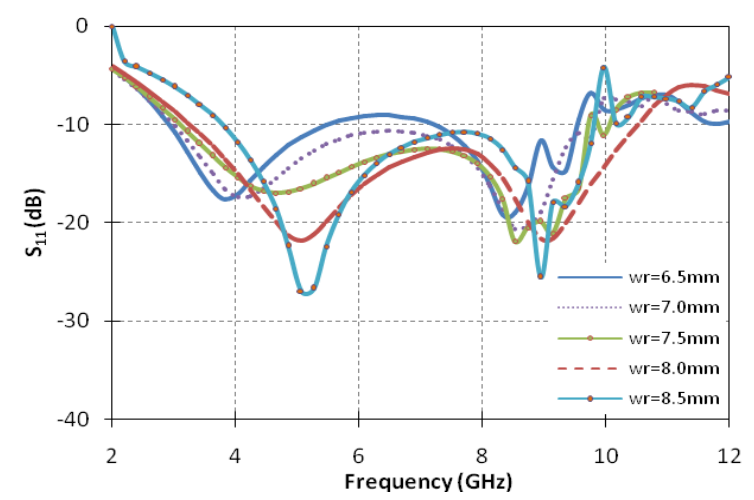

Figure 8: Return loss vs. frequency plot with variable rectangle height $\left(w_{r}\right)$.

Table 3. Effect of variation of rectangular base's height on bandwidth of proposed antenna.

\begin{tabular}{ccc}
\hline Step height $\left(\boldsymbol{h}_{\boldsymbol{r}}\right)(\mathbf{m m})$ & Frequency range (GHz) & Bandwidth (\%) \\
\hline 3.0 & $3.42-9.55$ & 94.59 \\
3.5 & $3.42-9.55$ & 94.59 \\
4.0 & $3.22-10.57$ & 106.67 \\
4.5 & $3.22-9.75$ & 100.77 \\
\hline
\end{tabular}

Table 4. Effect of variation of rectangular base's width on bandwidth of proposed antenna.

\begin{tabular}{ccc}
\hline Step height $\left(\boldsymbol{w}_{\boldsymbol{r}}\right)(\mathbf{m m})$ & Frequency range $(\mathbf{G H z})$ & Bandwidth $(\%)$ \\
\hline 6.5 & $2.81-5.46$ & 64.16 \\
7.0 & $3.02-9.75$ & 105.48 \\
7.5 & $3.22-9.75$ & 100.77 \\
8.0 & $3.22-10.57$ & 106.67 \\
8.5 & $3.63-9.95$ & 93.07 \\
\hline
\end{tabular}

The proposed geometry is simulated with HFSS software (pl. ref. its setup in Figure 1(b)) which is FDTD based electromagnetic (EM) software. Optimized parameters of the proposed geometry are listed in Table 5. 
Table 5. Optimized parameters of geometry shown in Figure 1.

\begin{tabular}{cc}
\hline Parameter & Value(mm) \\
\hline $\mathrm{W}$ & 26 \\
$\mathrm{~W}_{\mathrm{l}}$ & 22.7 \\
$\mathrm{~L}$ & 28 \\
$\mathrm{~L}_{\mathrm{g}}$ & 11.5 \\
$\mathrm{~W}_{\mathrm{g}}$ & 10.8 \\
$\mathrm{~W}$ & 2.5 \\
$\mathrm{~h}$ & 2.5 \\
$\mathrm{t}$ & 0.4 \\
$\mathrm{~W}_{\mathrm{r}}$ & 8.0 \\
$\mathrm{~h}_{\mathrm{r}}$ & 4.0 \\
$\mathrm{~W}_{\mathrm{s}}$ & 3.6 \\
$\mathrm{~h}_{\mathrm{g}}$ & 6.5 \\
\hline
\end{tabular}

\section{Experimental Validation of the Geometry and Discussions}

The geometry shown in Figure 1 with its optimized dimensions presented in Table 5 was fabricated and tested. The substrate used for the fabrication is the FR4 glass epoxy with dielectric constant of 4.4 , loss tangent $(\tan (\delta))$ $=0.02$, and thickness of $1.6 \mathrm{~mm}$. A photograph of the fabricated prototype is shown in Figure 9(a) and its $S_{11}$ measurement setup is shown in Figure 9(b). Return loss comparisons of measured and simulated values are compared in Figure 10. The measured results fairly agree with the simulated values.

From Figure 10 it may be noted that the proposed antenna is having the operating frequency range from $3.2 \mathrm{GHz}$ to $12 \mathrm{GHz}$. This corresponds to an impedance bandwidth of about $115 \%$. Radiation patterns of the geometry are presented at various frequencies in the band of operation (Figure 11). These patterns are symmetrical at the start and middle frequencies of the band of operation with omni-directional shape in the H-plane. However, at the end frequencies of operating band these patterns degrade. This degradation is mainly because of the change in the effective area over wide range of frequencies especially at high frequency end of operating band [18].

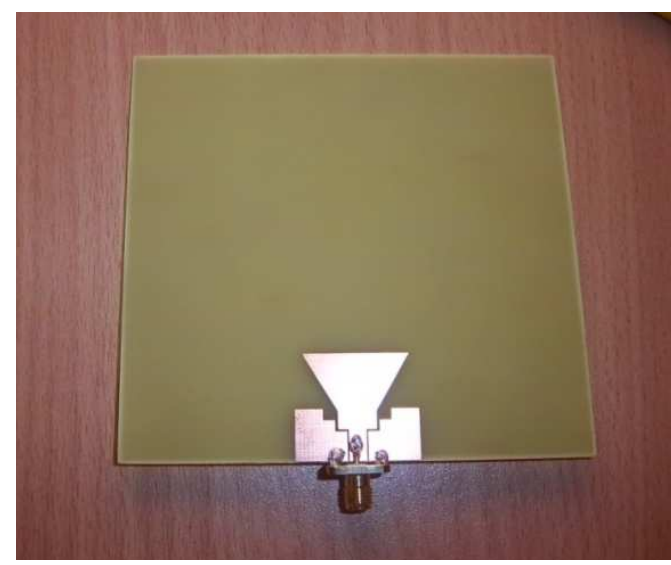

a) Fabricated prototype

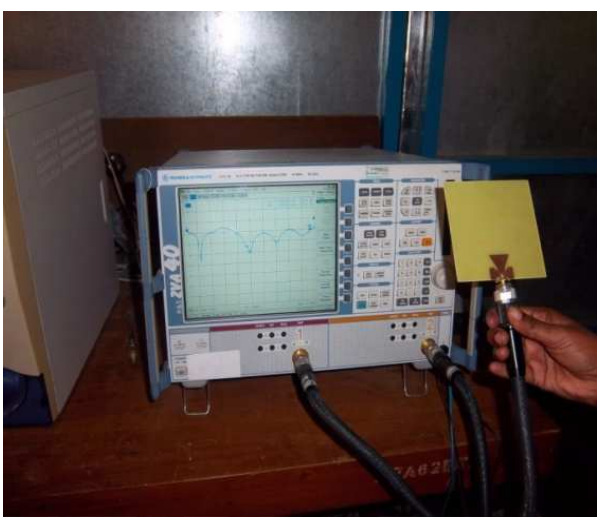

b) $S_{11}$ measurement setup

Figure 9. Photographs of the fabricated antenna and its measurement setup.

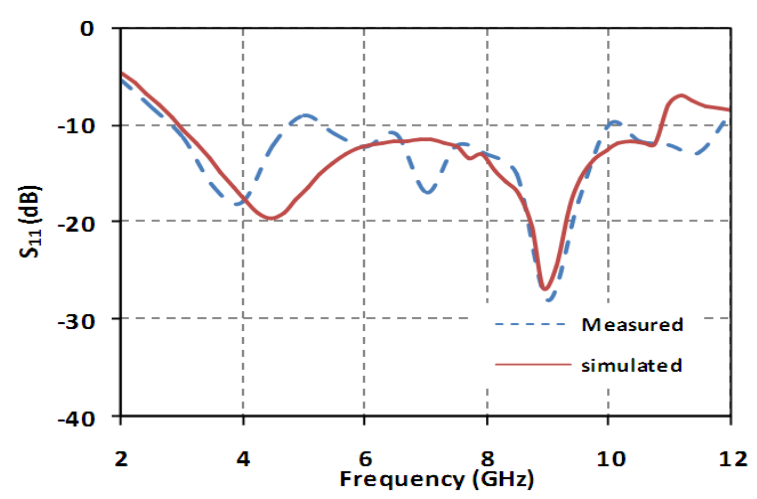

Figure 10. Return loss characteristic plot of the proposed antenna shown in Figure 1.
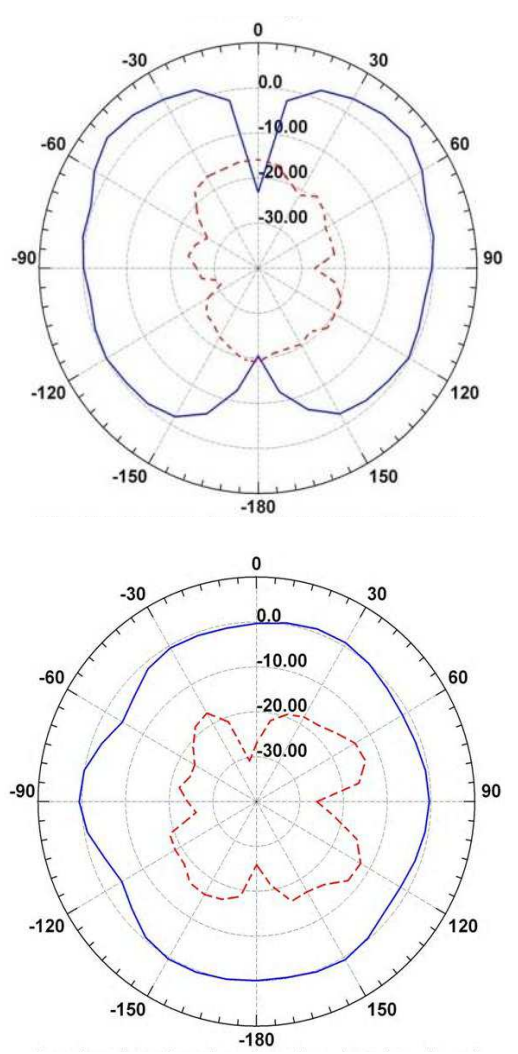

(a) E- and H-plane patterns at $3.0 \mathrm{GHz}$ 

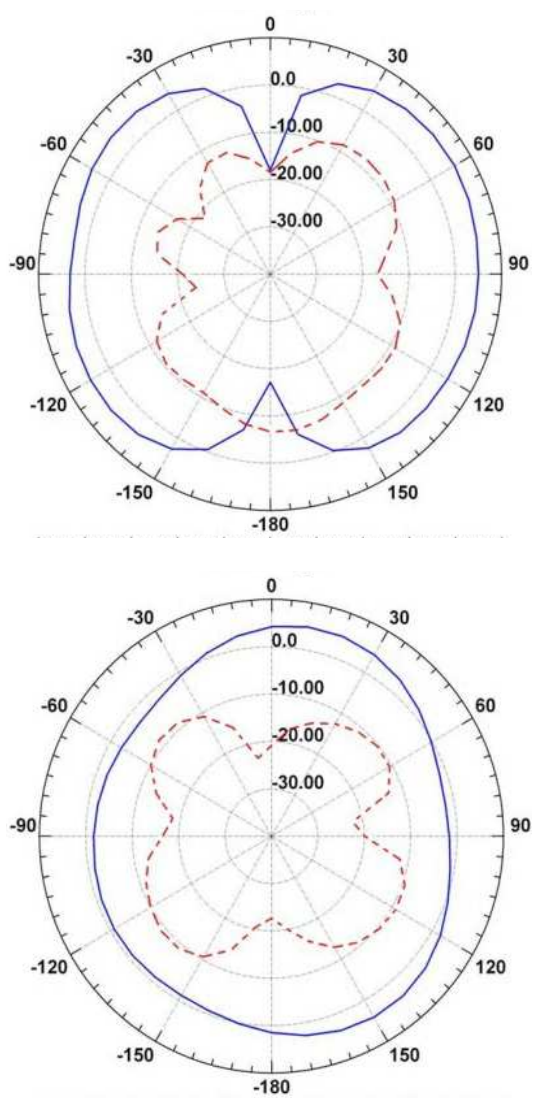

(b) E-and H-plane patterns at $6.7 \mathrm{GHz}$
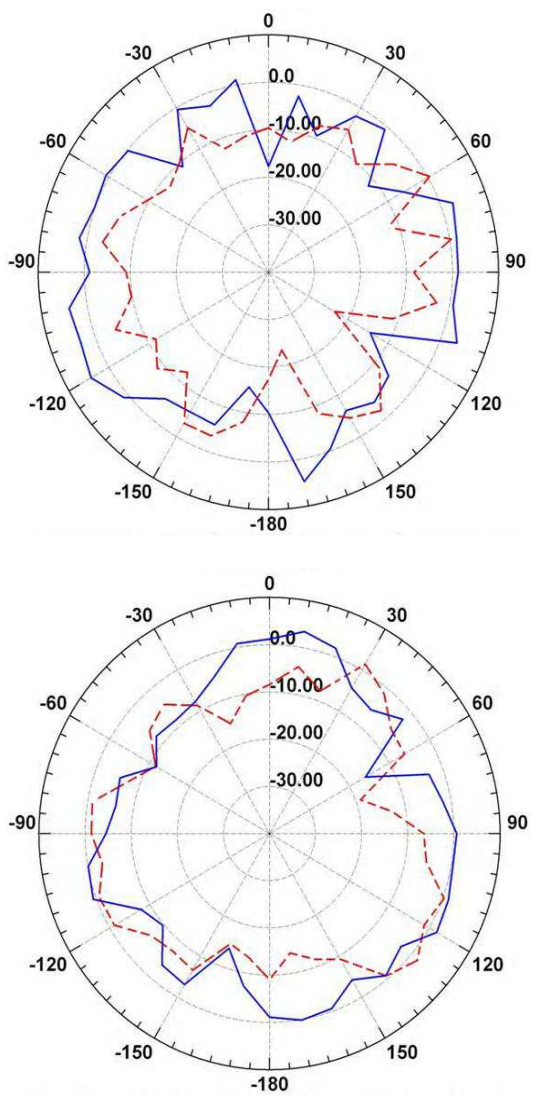

(c) E- and H-plane patterns at $10.5 \mathrm{GHz}$

Figure 11. $E$ - and $H$ - plane radiation patterns at various frequencies throughout the band of operation (Upper: E-plane patterns; Lower: H-plane patterns; Solid lines: Co-polarization patterns; Dashed lines: Cross-polarization patterns).

\section{Conclusions}

\section{References}

A triangular shaped monopole antenna mounted on rectangular base with finite ground has been presented. Staircase shaped ground geometry was varied (number of steps, step size, and step width) to tune antenna's input impedance. The antenna presented here offers an impedance bandwidth of more than $100 \%$ in the frequency range of $3.2 \mathrm{GHz}$ to $12 \mathrm{GHz}$ which essentially covers the FCC defined ultra wideband (UWB) frequency range. Omni-directional radiation patterns were obtained throughout the band of operation. Also, it was observed that for one step in the staircase shaped ground, the geometry offers dual band operation with better gain in the desired bands. Therefore, the antenna presented here is a suitable candidate for the FCC defined UWB band of operation.

\section{Acknowledgements}

We would like to thank Dr. C. Bhattacharya and his research students of Defence Institute of Advanced Studies (DIAT-DU), Girinagar, Pune, India for allowing and helping in measurements of fabricated prototypes.

[1] X. Y. Teng, X. M. Zhang, Z. X. Yang, Y. Wang, Y. Li, Q. F. Dai, and Z. Zhang, "A compact CPW-fed omni-directional monopole antenna for WLAN and RFID applications," Progress In Electromagnetics Research Letters, vol. 32, pp. 91-99, 2012.

[2] H. D. Chen and H. T. Chen, "A CPW-fed dual-frequency monopole antenna," IEEE Transactions on Antennas and Propagation, vol. 52, no. 4, pp. 978-982, 2004.

[3] G. Kumar and K. P. Ray, Broadband Microstrip Antennas, Artech House Boston, London.

[4] First Report and Order, Revision of part 15 of the commission's rule regarding ultra-wideband transmission systems FCC 02-48, Federal Communications Commission, 2002.

[5] K. C. gupta, R. Gerg, I. Bahl and P. Bhartia, Microstrip Lines and Slotline, Artech House, Boston, London.

[6] H. Zhang, H. Y. Xu, B. Tian, and X. F. Zeng, "CPW-fed fractal slot antenna for UWB application," Int. J. Antennas and Propagat., pp. 1-4, vol. 2012 (Article ID 129852).

[7] Z.-A. Zheng and Q.-X. Chu, "Compact CPW-fed UWB antenna with dual band notched characteristics," Progress In Electromagnetics Research Letters, vol. 11, pp. 83-91, 2009. 
[8] M. E. Jalil, M. K. Rahim, M. A. Abdullah, and O. Ayop, "Compact CPW-fed ultra-wideband (UWB) antenna using denim textile material," Proceedings of ISAP2012, Nagoya, Japan.

[9] T.-G. Ma and C.-H. Tseng, "An ultra wideband coplanar waveguide-fed tapered ring slot antenna," IEEE Trans. Antennas Propagat., vol. 54, no. 4, pp. 1105-1110, 2006.

[10] W.-P. Lin and C.-H. Huang, "Coplanar waveguide-fed rectangular antenna with an inverted-L stub for ultra wideband communications," IEEE Antennas and Wireless Propagation Letters, vol. 8, pp. 228-231, 2009.

[11] A. C. Shagar and R. S. D. Wahidabanu, "New design of CPW-fed rectangular slot antenna for ultra wideband applications," International Journal of Electronics Engineering, 2(1), pp. 69-73, 2010.

[12] R. V. Ram Krishna and R. Kumar, "Design of temple shape slot antenna for ultra wideband applications," Progress In Electromagnetics Research B, vol. 47, pp. 405-421, 2013.

[13] A. K. Gautam, S. Yadav, and B. K. Kanaujia, “A CPW-Fed compact UWB microstrip antenna," IEEE Antennas and Wireless Propagation Letters, vol. 12, pp. 151-154, 2013.

[14] J. Pourahmadazar, Ch. Ghobadi, J. Nourinia, N. Felegari, and H. Shirzad, "Broadband CPW-fed circularly polarized square slot antenna with inverted-L strips for UWB applications," IEEE Antennas and Wireless Propagation Letters, vol. 10, pp. 369-372, 2011.

[15] HFSS10.0 User's Manual, Ansoft Corporation, Pittsburgh.

[16] M. N. Moghadasi, R. Sadeghzadeh, L. Asadpor, and B. S. Virdee, "A small dual-band CPW fed monopole antenna for GSM and WLAN applications," IEEE Antennas and Propoagat. Lett., vol. 12, pp. 508-511, 2013.

[17] L. H. Weng, Y. C. Guo, X. W. Shi, and X. Q. Chen, "An overview on defected ground structure," Progress In Electromagnetics Research B, vol. 7, pp. 173-189, 2008.

[18] X. -C. Yin, C. -L. Ruan, C. -Y. Ding, and J. -H. Chu, "A planar U type monopole antenna for UWB applications," Progress In Electromagnetics Research Letters, vol. 2, pp. 1-10, 2008. 